
\title{
S Research Square \\ Gastric Cancer Stem Cells Survive in Stress Environments via Their Autophagy System
}

\section{Shingo Togano}

Department of Gastroenterological Surgery, Osaka City university Graduate School of Medicine Masakazu Yashiro ( $\nabla$ m9312510@med.osaka-cu.ac.jp )

Department of Surgical Oncology, Osaka City University Graduate School of Medicine https://orcid.org/0000-0001-5743-7228

\section{Go Masuda}

Department of Gastroenterological Surgery, Osaka City University Graduate School of Medicine

\section{Atsushi Sugimoto}

Department of Gastroenterological Surgery, Osaka City University Graduate School of Medicine

\section{Yuichiro Miki}

Department of Gastroenterological Surgery, Osaka City University Graduate School of Medicine

\section{Yurie Yamamoto}

Molecular Oncology and Therapeutics, Osaka City University Graduate School of Medicine

\section{Tomohiro Sera}

Department of Gastroenterological Surgery, Osaka City University Graduate School of Medicine

\section{Shuhei Kushiyama}

Department of Gastroenterological Surgery, Osaka City University Graduate School of Medicine

\section{Sadaaki Nishimura}

Department of Gastroenterological Surgery, Osaka City University Graduate School of Medicine

\section{Kenji Kuroda}

Department of Gastroenterological Surgery, Osaka City University Graduate School of Medicine

\section{Tomohisa Okuno}

Department of Gastroenterological Surgery, Osaka City University Graduate School of Medicine

\section{Masaichi Ohira}

Department of Gastroenterological Surgery, Osaka City University Graduate School of Medicine

\section{Research article}

Keywords: Gastric cancer, cancer stem cells, autophagy, autophagy inhibitor, chloroquine

Posted Date: October 13th, 2020

DOI: https://doi.org/10.21203/rs.3.rs-91127/v1 
License: (c) (i) This work is licensed under a Creative Commons Attribution 4.0 International License. Read Full License

Version of Record: A version of this preprint was published at Scientific Reports on October 19th, 2021. See the published version at https://doi.org/10.1038/s41598-021-00155-3. 


\section{Abstract}

Background: It has been reported that cancer stem cells (CSCs) play an important role in the progression of carcinoma and have a high potential for survival in various stress environments such as starvation and hypoxia. However, the mechanisms responsible for the capacity of CSCs to survive under stresses have been unclear. The aim of this study was to clarify the significance of the autophagy systems of CSCs under stress environments.

Methods: Four human gastric cancer cell line, OCUM-12, OCUM-2MD3, MKN-45 and MKN-74 were used. Side population (SP) cells were sorted from the parent OCUM-12 and OCUM-2MD3, as CSC rich cells. The expression of stem cell markers was examined by RT-PCR. The viability of cancer cells under starvation and hypoxia $\left(1 \% \mathrm{O}_{2}\right)$ was evaluated by MTT assay with or without the autophagy inhibitor, chloroquine. The expression level of the autophagy molecule LC3-II was examined by western blot. The numbers of autophagosomes and autolysosomes were counted by electron microscope.

Results: SP cells of OCUM-12 showed a higher expression of stem cell markers and higher viability in starvation and hypoxia. Western blot and electron microscope examinations indicated that the autophagy was more induced in SP cells than in parent cells. The autophagy inhibitor significantly decreased the viability and the proportion of SP cells under the stress environments.

Conclusions: Cancer stem cells of gastric cancer might maintain their viability under stress environments of starvation and hypoxia via the autophagy system. Autophagy inhibitors might be a promising therapeutic agent for gastric cancer.

\section{Introduction}

It has been reported that cancer stem cells (CSCs), a unique subpopulation in tumors, play an important role for the progression of carcinomas [1-3]. CSCs has been known to be the prime sources of selfrenewal, and to supply cancer cells [4-6]. CSCs have a high potential to survive various stresses such as starvation and hypoxia, resulting the increase of the proportion of CSCs [6, 7]. However, the mechanisms responsible for the high survival capacity of CSCs under these stresses has remained to be unclear. The side population (SP) of cancer cells evaluated by flow cytometric analysis is known as a CSC-rich population. SP cells might be useful for the stemness of various carciunomas [8-10].

Autophagy is an intracellular degradation and re-use system which is induced under various stresses such as starvation and hypoxia; it is a so-called "self-eating process" involving intracellular proteins, complexes, or organelles in the autophagosome [11-13]. The autophagosome is transported and fuses with the lysosome to generate the autolysosome, and the components are degraded by acidic hydrolases. The degradation products, including nucleotides, amino acids, fatty acids, and sugars are transported back and recycled into the general cell metabolism $[11,14]$. It has been reported that the autophagy systems involved in cancer might be associated with the survival of cancer cells [15]. However, the significance of the autophagy system of CSCs, especially under stress conditions, remains unclear. We 
then aimed to clarify the significance of the autophagy systems of CSCs in stress environments such as starvation and hypoxia in this study.

\section{Methods}

\section{Cell line}

Four human gastric cancer cell line, OCUM-12 (RRID: CVCL_8380), OCUM-2MD3 (RRID: CVCL_8385), MKN-45 (RRID: CVCL_0434) and MKN-74 (RRID: CVCL_2791) were used as parent cells. OCUM-12 [16] and OCUM-2MD3 [17] were established at our laboratory. MKN-45 and MKN-74 were provided from JCRB Cell Bank [18] (Osaka, Japan). All cell lines in this study were authenticated by STR profiling before distribution.

\section{Cell culture}

Cells were cultured with each medium or condition: Dulbecco's modified Eagle medium (DMEM) with high glucose $4500 \mathrm{mg} / \mathrm{L}$ and 16 amino acids (WAKO, Osaka, Japan) and 10\% Fetal bovine serum (FBS; SIGMA, St. Louis, MO) as control medium, DMEM with low glucose $1000 \mathrm{mg} / \mathrm{L}$ and 16 amino acids and $10 \%$ FBS as low-glucose medium, DMEM with high glucose $4500 \mathrm{mg} / \mathrm{L}$ and no amino acids (WAKO) and $10 \%$ FBS as amino-acid-free medium, DMEM with high glucose $4500 \mathrm{mg} / \mathrm{L}$ and 16 amino acids, without FBS as FBS-free medium. These media were also contained penicillin and streptomycin, and $0.5 \mathrm{mM}$ sodium pyruvate, and were incubated at $37^{\circ} \mathrm{C}$ under $21 \%$ oxygen condition. Another condition was hypoxia: the control medium under $1 \% \mathrm{O}_{2}$. This study was approved by the Osaka City University ethics committee (approval number 924).

\section{SP analysis using flow cytometry}

SP cells were defined as the subset of cells that exhibited a low Hoechst33342 (SIGMA) staining pattern and disappeared with use of verapamil (SIGMA), as previously reported $[8,10,19]$. The cancer cells were suspended at $5 \times 10^{5}$ cells $/ \mathrm{mL}$ in DMEM. These cells were then incubated at $37^{\circ} \mathrm{C}$ with agitation in water bath for $60 \mathrm{~min}$ with $5 \mu \mathrm{g} / \mathrm{mL}$ Hoechst 33342, either alone or in the presence of $50 \mu \mathrm{g} / \mathrm{mL}$ verapamil. After incubation, $1 \mu \mathrm{g} / \mathrm{mL}$ Propidium iodide (Becton Dickinson, Franklin Lakes, NJ, USA) was added and then filtered through a $40 \mu \mathrm{g}$ cell strainer (Becton Dickinson) to obtain single-suspension cells. Analyses and sorting were performed using BD FACSAria II (Becton Dickinson). Hoechst red and blue are optical filters for measuring fluorescence emission. Hoechst 33342 was excited with the UV laser at $350 \mathrm{~nm}$, and fluorescence emission was measured with 405 = BP30 (Hoechst blue) and $570=$ BP20 (Hoechst red) optical filters. The SP cells, which disappear in the presence of verapamil, are outlined and shown as a percentage of the total cell population.

\section{Quantitative real-time reverse transcription-polymerase chain reaction (RT-PCR)}

RT-PCR was performed as follows. A total of $1 \times 10^{5}$ number of SP cells were sorted by flow cytometry. The total cellular RNA of parent cells and SP cells was extracted using Trizol reagent (Invitrogen, Carlsbad, CA, USA) and Direct-zol ${ }^{\mathrm{TM}}$ RNA MiniPrep (Zymo Research, Irvine, California, USA). cDNA was 
prepared from $1000 \mu \mathrm{g}$ RNA using ReverTra Ace qPCR RT Master Mix (TOYOBO, Osaka, JAPAN). Quantitative real-time PCR was performed using the THUNDERBIRD SYBR qPCR MIX (TOYOBO). Aliquots of cDNA were amplified for 40 cycles consisting of 15 second of denaturing at $95^{\circ} \mathrm{C}, 60$ second of annealing and extension at $60{ }^{\circ} \mathrm{C}$. Each PCR was performed in triplicate. The expression of each human gene was then normalized using ACT $\beta$ expression as an internal control.

To determine fold changes in each gene, RT-PCR was performed on the ABI Prism 7500 (Applied Biosystems, Foster City, CA, USA), with commercially available gene expression assays (Applied Biosystems) for, CD44, CD133, SOX2, NANOG, and ATP-binding cassette, sub-family G, member 2 (ABCG2). ACT $\beta$ was used as an internal standard to normalize mRNA levels. The primer sequences were listed in Supporting information.

\section{Effect of starvation or hypoxia and chloroquine on SP fraction}

Each cell was incubated $12 \mathrm{~h}$ in each medium or hypoxia, either alone or in the presence of $10 \mu \mathrm{M}$ chloroquine (CQ; SIGMA). Cells were suspended at $5 \times 10^{5}$ cells $/ \mathrm{mL}$ in PBS. SP fraction was analyzed by flow cytometry.

\section{Cell growth assay and cytotoxic assay}

The proliferation of parent cells and SP cells and cytotoxicity of CQ were quantified using an MTT colorimetric assay (Dojindo, Kumamoto, Japan). Each cell was seeded at a cell density of $1.5 \times 10^{3} /$ well in 96-well plates in each medium and hypoxia, and incubated $96 \mathrm{~h}$ at $37^{\circ} \mathrm{C}$ for proliferation assay. For cytotoxicity assay, each cell was seeded at a cell density of $3.0 \times 10^{3} /$ well in 96 -well plates in each medium and hypoxia with or without $10 \mu \mathrm{M} \mathrm{CQ}$, and incubated $48 \mathrm{~h}$ at $37^{\circ} \mathrm{C}$. MTT solution was added to each well at $500 \mu \mathrm{g} / \mathrm{ml}$. The cells were incubated for $2 \mathrm{~h}$ and lysed in dimethyl sulfoxide and the absorbance value was analyzed using a Varioskan LUX (Thermo Fisher scientific, Waltham, MA, USA) at a wavelength of $535 \mathrm{~nm}$.

\section{Western blot analysis}

Each cell was seeded at a cell density of $5.0 \times 10^{4} /$ well in 6-well plates under each medium or hypoxia in absence (-CQ) or presence (+CQ) of $10 \mu \mathrm{M} \mathrm{CQ}$ and incubated $6 \mathrm{~h}$ at $37^{\circ} \mathrm{C}$. Cell lysates were made by standard methods. The protein concentration of each sample was measured using a Bio-Rad protein assay kit II (Bio-Rad Laboratory, Richmond, CA, USA). For SDS-PAGE, $2.5 \mu \mathrm{g}$ of proteins from each sample were subjected to electrophoresis on $10-15 \%$ polyacrylamide gels. Proteins were electrophoretically transferred to polyvinylidene difluoride membranes with a tank transfer systems (Bio-Rad Laboratory), then blocked with buffer containing 3.0\% skim-milk and $0.1 \%$ Tween-20 in Tris-buffered saline (TBST) at room temperature for $1 \mathrm{~h}$. Primary antibody of a microtubule-associated protein-light chain 3B (LC3B; L7543, SIGMA) was used at 1:1000 dilution, GAPDH (sc-47724, Santa Cruz, Dallas, TX) was used at 1:5000 dilution in TBST containing 3.0\% skim-milk. The membranes were incubated with primary antibody overnight at $4^{\circ} \mathrm{C}$, washed $(3 \times 5 \mathrm{~min})$ with TBST, followed by incubation with a horseradish peroxidase-conjugated secondary antibodies (NA931V and NA934V, GE Healthcare, Chicago, IL, USA) in 
TBST for $1 \mathrm{~h}$ at room temperature, then washed $(3 \times 10 \mathrm{~min})$ with washing buffer. Detection of chemiluminescence was performed with immunoStar LD (WAKO) following the manufacturer's instructions. Band intensity were estimated using ImageQuant TL (GE).

\section{Counting the autophagy flux by electron microscope}

Each cell was incubated $12 \mathrm{~h}$ in control medium or FBS-free medium, and was trypsinized and pelleted. The cells were then suspended and fixed $30 \mathrm{~min}$ at $4{ }^{\circ} \mathrm{C}$ in $2.5 \%$ glutaraldehyde with $2 \%$ paraformaldehyde in $0.1 \% \mathrm{M}$ Phosphate buffer. The cells were then rinsed 4 times in $0.1 \% \mathrm{M}$ Phosphate buffer and spun down into $3 \%$ agarose at $55^{\circ} \mathrm{C}$, and cooled to form blocks. The agarose blocks were incubated in $1 \%$ osmium tetroxide in $0.1 \mathrm{MPB}$ for $2 \mathrm{~h}$ at room temperature. The agarose blocks were rinsed 4 times in $0.1 \%$ MPB and dehydrated in graded steps of alcohol and embedded in propylene oxide. Following polymerization overnight at $60^{\circ} \mathrm{C}, 80$-nm sections were cut on a UltracutUCT (Leica,Wien, Austria) and picked up on copper grids. The grids were post-stained in uranyl acetate and Reynolds solution. The sections were observed in a Talos F200C (FEl, Hillsboro, OR, USA). The numbers of autophagosomes and autolysosomes in 10 cells was counted under each condition.

\section{Statistical Analysis}

The statistical analysis was done using the Student's t-test. Statistical significance was set at $\leq 0.05$.

\section{Results}

\section{SP fraction in 4 cell lines}

SP cells were defined as the population that disappeared with the administration of verapamil $(\leq 1 \%)$. Figure 1 shows representative pictures of the SP fraction determined by flow cytometric analysis. The SP percentage of the parent OCUM-12, OCUM-2MD3, MKN-45 and MKN-74 cells was $5.6 \%, 6.0 \%, 1.2 \%$ and $1.7 \%$, respectively. The SP percentage of SP cells at 1 hour after the sorting of the parent OCUM-12 cells (OCUM-12/SP cells) was $91.0 \%$, which suggested that most of the cells sorted by flow cytometry were SP cells.

\section{Stem cell marker expression in parent cells and SP cells}

The mRNA expression levels of SOX2, NANOG, and ABCG2 were significantly higher in the OCUM-12/SP cells than in the parent OCUM-12 cells. On the other hand, no significant difference of stem cell markers was found between the parent OCUM-2MD3 cells and the OCUM-2MD3/SP cells. (Fig. 2A).

\section{Effect of starvation and hypoxic stress on the proliferation of OCUM-12 cells}

We examined the effect of starvation and hypoxic stress on the proliferation activity of the parent OCUM12 cells and the OCUM-12/SP cells. The proliferative activity of the OCUM-12/SP cells was significantly higher than that of the parent OCUM-12 cells in amino-acid-free medium, FBS-free medium, and under a $1 \% \mathrm{O}_{2}$ condition, but not in a low-glucose medium (Fig. 2B). 
The effect of starvation and hypoxic stress on the SP fraction was analyzed by flow cytometry. Starvation stress and hypoxia significantly increased the SP fraction (Figs. 3A and 3B). The SP fraction observed when using the low-glucose medium, amino-acid-free medium, FBS-free medium, and $1 \% \mathrm{O}_{2}$ condition was significantly higher than that of the control.

\section{Effect of starvation and hypoxic stress on autophagy}

The LC3-II expression in the parent OCUM-12 cells was greatest when using the amino-acid-free medium, while that in the OCUM-12/SP cells was greatest with the FBS-free medium. With the control medium and low-glucose medium, the LC3-II expression was slight in both types of cells. The LC3-II expression when using the amino-acid-free medium, FBS-free medium, and $1 \% \mathrm{O}_{2}$ condition was higher in the OCUM-12/SP cells than in the parent OCUM-12 cells, and the difference in LC3-II expression was greatest with the FBSfree medium (Fig. 4A and 4B). In addition, the numbers of autophagosomes and autolysosomes were counted using an electron microscope (Fig. 5A). A significant increase $(p=0.011)$ in the numbers of autophagosomes and autolysosomes in OCUM-12/SP cells was observed when using the FBS-free medium, while no significant difference was found in the control medium (Fig. 5B).

\section{The effect of an autophagy inhibitor, CQ, on the proliferation of OCUM-12 cells}

The proliferation activity of OCUM-12/SP cells in the amino-acid-free medium, FBS-free medium, and under the $1 \% \mathrm{O}_{2}$ condition was significantly decreased following the addition of the autophagy inhibitor, CQ, in comparison to the parent OCUM-12 cells (Fig. 6A).

\section{The effect of CQ on the proportion of SP cells}

CQ reduced the SP fraction. CQ combined with amino-acid-free medium, FBS-free medium, and under the $1 \% \mathrm{O}_{2}$ condition greatly reduced the SP fraction compared to the control medium (Fig. 6B and 6C).

\section{Discussion}

We aimed to clarify the significance of the autophagy systems of CSCs under stress environments such as starvation and hypoxia. It has been reported that SP cells of gastric cancer possess cancer stem-like properties $[8,9]$. We then used the SP cells of OCUM-12, OCUM-2MD3, MKN-45 and MKN-74 cells as CSCs in this study. Since MKN-45 cells and MKN-74 cells have few SP fractions, MKN-45 and MKN-74 were excluded from the following examinations. The SP percentage of OCUM-12/SP cells sorted by flow cytometry was $91.0 \%$, while that of the parent OCUM-12 cells was $5.6 \%$, which suggested that flow cytometry could successively select SP cells. Next, we evaluated the stemness of the OCUM-12/SP cells and the OCUM-2MD3/SP cells by RT-PCR using stem cell markers. The OCUM-12/SP cells showed higher expression of SOX2, NANOG and ABCG2, in comparison to the parent OCUM-12 cells. In contrast, no significant difference of stem cell markers was found between the parent OCUM-2MD3 cells and the OCUM-2MD3/SP cells. Then, OCUM-2MD3 was unfortunately excluded from the following study because the evidence of stemness of OCUM-2MD3/SP cells is necessary for the following examinations. The OCUM-12/SP cells could survive under stress conditions such as free amino acid, free FBS, or hypoxia in 
comparison to the parent OCUM-12 cells. These findings suggested that the OCUM12/SP cells possess cancer stem-like properties, as previously reported [8].

LC3-I is conjugated and forms LC3-II, which is recruited to autophagosomal membranes.

Autophagosomes fuse with lysosomes to form autolysosomes and are degraded by lysosomal

hydrolases. The autophagosomal marker LC3-II reflects starvation-induced autophagic activity [20].

Western blot of LC3-II indicated that the autophagy system was induced in both the parent cells and SP cells in FBS starvation, amino acid starvation, and hypoxia $\left(1 \% \mathrm{O}_{2}\right.$ condition), but that of SP cells was greater than that of parent cells. The growth activity of SP cells was greater than that of parent cells under these stress environments. These findings might suggest that the survival potential of CSCs was greater than parent cells inducing autophagy system.

The autophagy inhibitor, CQ, significantly decreased the growth activity of the OCUM-12/SP cells under FBS starvation, amino acid starvation, and hypoxia $\left(1 \% \mathrm{O}_{2}\right.$ condition), in compared to the parent OCUM-12 cells. The heterogenicity of starvation and hypoxic lesions in the tumor microenvironment is often associated with malignant transformation of solid tumors [16]. CSCs might survive under these stress environments via autophagy systems, and the CQ might decrease the survival activity of the CSCs of gastric cancer under stress environments. There are only two reports about the effect of CQ on CSCs in ovarian cancer [21] and hepatocellular carcinoma [22]. This is the first report of the inhibitory effect of the autophagy inhibitor, CQ, on the proliferation of gastrointestinal CSCs. Gastrointestinal CSCs have been proposed to play an important role in the progression of carcinomas including the metastasis and chemoresistance of cancer cells. These findings suggested that the autophagy inhibitor might be useful for advanced stage patients with metastatic carcinoma or chemo-resistant gastric carcinoma.

In conclusion, CSCs of gastric cancer might maintain their viability under the stress environments of starvation and hypoxia via the autophagy system. Autophagy inhibitors might be promising therapeutic agents for gastric cancer.

\section{Abbreviations}

CSCs cancer stem cells

SP side population

LC3B microtubule-associated protein-light chain 3B

DMEMDulbecco's modified Eagle medium

FBS Fetal bovine serum

RT-PCR quantitative real-time reverse transcription-polymerase chain reaction

ABCG2 ATP-binding cassette, sub-family G, member 2 
CQ chloroquine

TBST Tween-20 in Tris-buffered saline

\section{Declarations}

Ethics approval and consent to participate

This study was approved by the Osaka City University ethics committee (approval number 924).

\section{Consent for publication}

Not applicable.

\section{Availability of data and materials}

The datasets used and analysed during the current study are available from the corresponding author on reasonable request.

\section{Competing interests}

The authors declare that they have no competing interests.

\section{Funding}

This work was supported by KAKENHI Grant-in-Aid for Scientific Research, Nos. 18H02883(M.Y.).

This funding contributed to the design of the study and collection.

\section{Authors' contributions}

ST: study conception and design, acquisition of data, analysis and interpretation of data, drafting manuscript.

MY: study conception and design, acquisition of data, analysis and interpretation of data, drafting manuscript.

GM, AS, YM, YY, TS, SK, SN, KK, TO, MO: Drafting and revisiting manuscript, and interpretation of the results.

All authors read and approved the final manuscript.

\section{Acknowledgements}

We thank Kayo Tsubota (Molecular Oncology and Therapeutics), Akiko Tsuda (Molecular Oncology and Therapeutics), Yukimi Kira, Yoriko Yabunaka and Hideo Nakagawa (Research Support Platform ) at 
Osaka City University Graduate School of Medicine) for technical support.

\section{References}

1. O'Connor ML, Xiang D, Shigdar S, Macdonald J, Li Y, Wang T, Pu C, Wang Z, Qiao L, Duan W: Cancer stem cells: A contentious hypothesis now moving forward. Cancer letters 2014, 344(2):180-187.

2. Wang T, Shigdar S, Gantier MP, Hou Y, Wang L, Li Y, Shamaileh HA, Yin W, Zhou SF, Zhao X et al: Cancer stem cell targeted therapy: progress amid controversies. Oncotarget 2015, 6(42):4419144206.

3. Du FY, Zhou QF, Sun WJ, Chen GL: Targeting cancer stem cells in drug discovery: Current state and future perspectives. World journal of stem cells 2019, 11(7):398-420.

4. Keith B, Simon MC: Hypoxia-inducible factors, stem cells, and cancer. Cell 2007, 129(3):465-472.

5. Krishnamurthy P, Ross DD, Nakanishi T, Bailey-Dell K, Zhou S, Mercer KE, Sarkadi B, Sorrentino BP, Schuetz JD: The stem cell marker Bcrp/ABCG2 enhances hypoxic cell survival through interactions with heme. The Journal of biological chemistry 2004, 279(23):24218-24225.

6. Tavaluc RT, Hart LS, Dicker DT, El-Deiry WS: Effects of low confluency, serum starvation and hypoxia on the side population of cancer cell lines. Cell Cycle 2007, 6(20):2554-2562.

7. Lee E, Yang J, Ku M, Kim NH, Park Y, Park CB, Suh JS, Park ES, Yook JI, Mills GB et al: Metabolic stress induces a Wnt-dependent cancer stem cell-like state transition. Cell Death Dis 2015, 6:e1805.

8. Hasegawa T, Yashiro M, Nishii T, Matsuoka J, Fuyuhiro Y, Morisaki T, Fukuoka T, Shimizu K, Shimizu T, Miwa A et al: Cancer-associated fibroblasts might sustain the stemness of scirrhous gastric cancer cells via transforming growth factor-beta signaling. Int J Cancer 2014, 134(8):1785-1795.

9. Nishii T, Yashiro M, Shinto O, Sawada T, Ohira M, Hirakawa K: Cancer stem cell-like SP cells have a high adhesion ability to the peritoneum in gastric carcinoma. Cancer science 2009, 100(8):13971402.

10. Fukuda K, Saikawa Y, Ohashi M, Kumagai K, Kitajima M, Okano H, Matsuzaki Y, Kitagawa Y: Tumor initiating potential of side population cells in human gastric cancer. International journal of oncology 2009, 34(5):1201-1207.

11. Liu G, Pei F, Yang F, Li L, Amin AD, Liu S, Buchan JR, Cho WC: Role of Autophagy and Apoptosis in Non-Small-Cell Lung Cancer. International journal of molecular sciences 2017, 18(2).

12. Nazio F, Bordi M, Cianfanelli V, Locatelli F, Cecconi F: Autophagy and cancer stem cells: molecular mechanisms and therapeutic applications. Cell Death \& Differentiation 2019.

13. Mizushima N, Komatsu M: Autophagy: renovation of cells and tissues. Cell 2011, 147(4):728-741.

14. Kimmelman AC, White E: Autophagy and Tumor Metabolism. Cell metabolism 2017, 25(5):10371043.

15. Sato K, Tsuchihara K, Fujii S, Sugiyama M, Goya T, Atomi $Y$, Ueno T, Ochiai A, Esumi H: Autophagy is activated in colorectal cancer cells and contributes to the tolerance to nutrient deprivation. Cancer Res 2007, 67(20):9677-9684. 
16. Kato Y, Yashiro M, Noda S, Tendo M, Kashiwagi S, Doi Y, Nishii T, Matsuoka J, Fuyuhiro Y, Shinto 0 et al: Establishment and characterization of a new hypoxia-resistant cancer cell line, OCUM-12/Hypo, derived from a scirrhous gastric carcinoma. Br J Cancer 2010, 102(5):898-907.

17. Yashiro M, Chung YS, Nishimura S, Inoue T, Sowa M: Peritoneal metastatic model for human scirrhous gastric carcinoma in nude mice. Clinical \& experimental metastasis 1996, 14(1):43-54.

18. Motoyama $\mathrm{T}$, Hojo $\mathrm{H}$, Watanabe $\mathrm{H}$ : Comparison of seven cell lines derived from human gastric carcinomas. Acta pathologica japonica 1986, 36(1):65-83.

19. Schmuck R, Warneke V, Behrens HM, Simon E, Weichert W, Rocken C: Genotypic and phenotypic characterization of side population of gastric cancer cell lines. The American journal of pathology 2011, 178(4):1792-1804.

20. Mizushima N, Yoshimori T: How to Interpret LC3 Immunoblotting. Autophagy 2014, 3(6):542-545.

21. Pagotto A, Pilotto G, Mazzoldi EL, Nicoletto MO, Frezzini S, Pasto A, Amadori A: Autophagy inhibition reduces chemoresistance and tumorigenic potential of human ovarian cancer stem cells. Cell Death Dis 2017, 8(7):e2943.

22. Song YJ, Zhang SS, Guo XL, Sun K, Han ZP, Li R, Zhao QD, Deng WJ, Xie XQ, Zhang JW et al: Autophagy contributes to the survival of CD133+ liver cancer stem cells in the hypoxic and nutrientdeprived tumor microenvironment. Cancer Lett 2013, 339(1):70-81.

\section{Figures}

Figure 1. Togano S. et al.

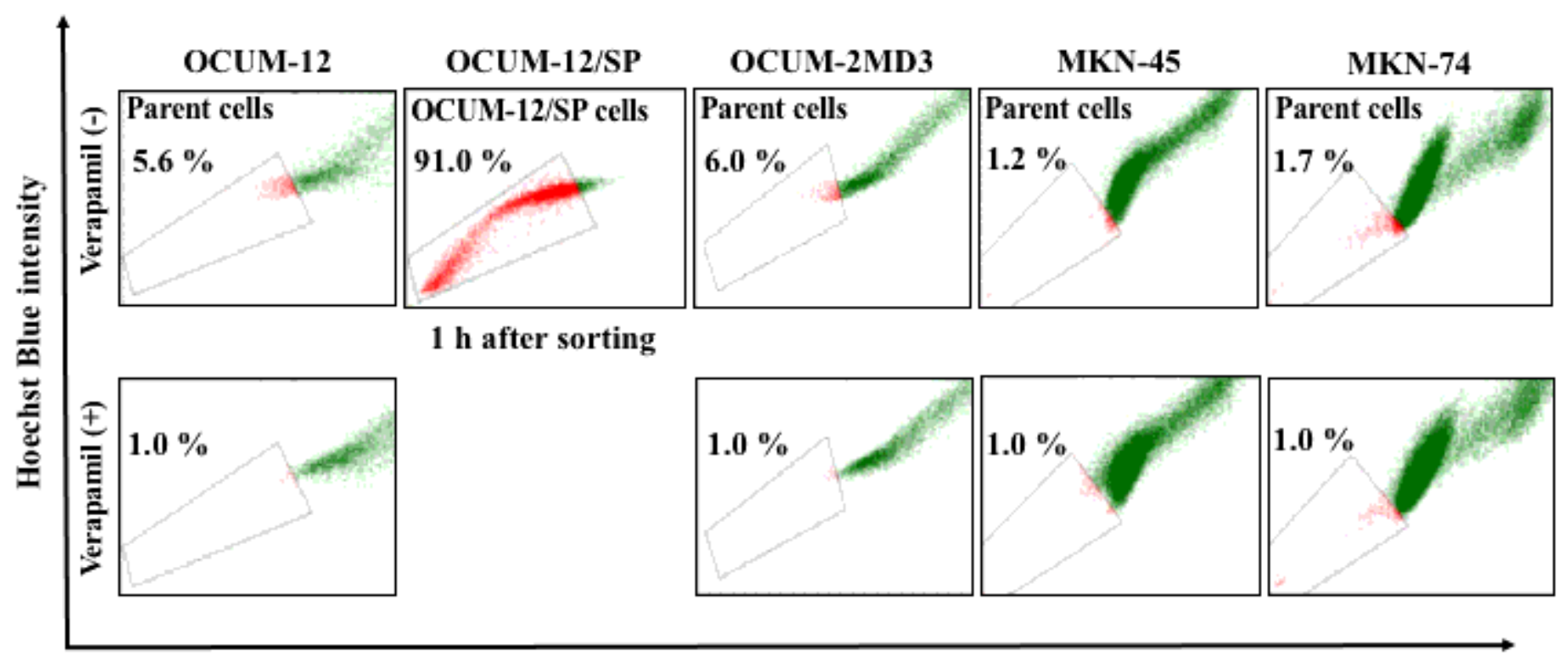

Hoechst Red intensity

Figure 1 
Representative picture of SP fraction. Cancer cells, which disappear in the presence of verapamil, are outlined and defined as the SP cells. The SP percentage of the parent OCUM-12, OCUM-2MD3, MKN-45 and MKN-74 cells was $5.6 \%, 6.0 \%, 1.2 \%$ and $1.7 \%$, respectively. Since MKN-45 cells and MKN-74 cells have few SP fractions, MKN-45 and MKN-74 were excluded from the following examinations. To confirm the sorting accuracy, sorted SP cells of the parent OCUM-12 cells were re-analyzed 1 hour later. The SP percentage of OCUM-12/SP was $91.0 \%$.

Figure 2. Togano S. et al.
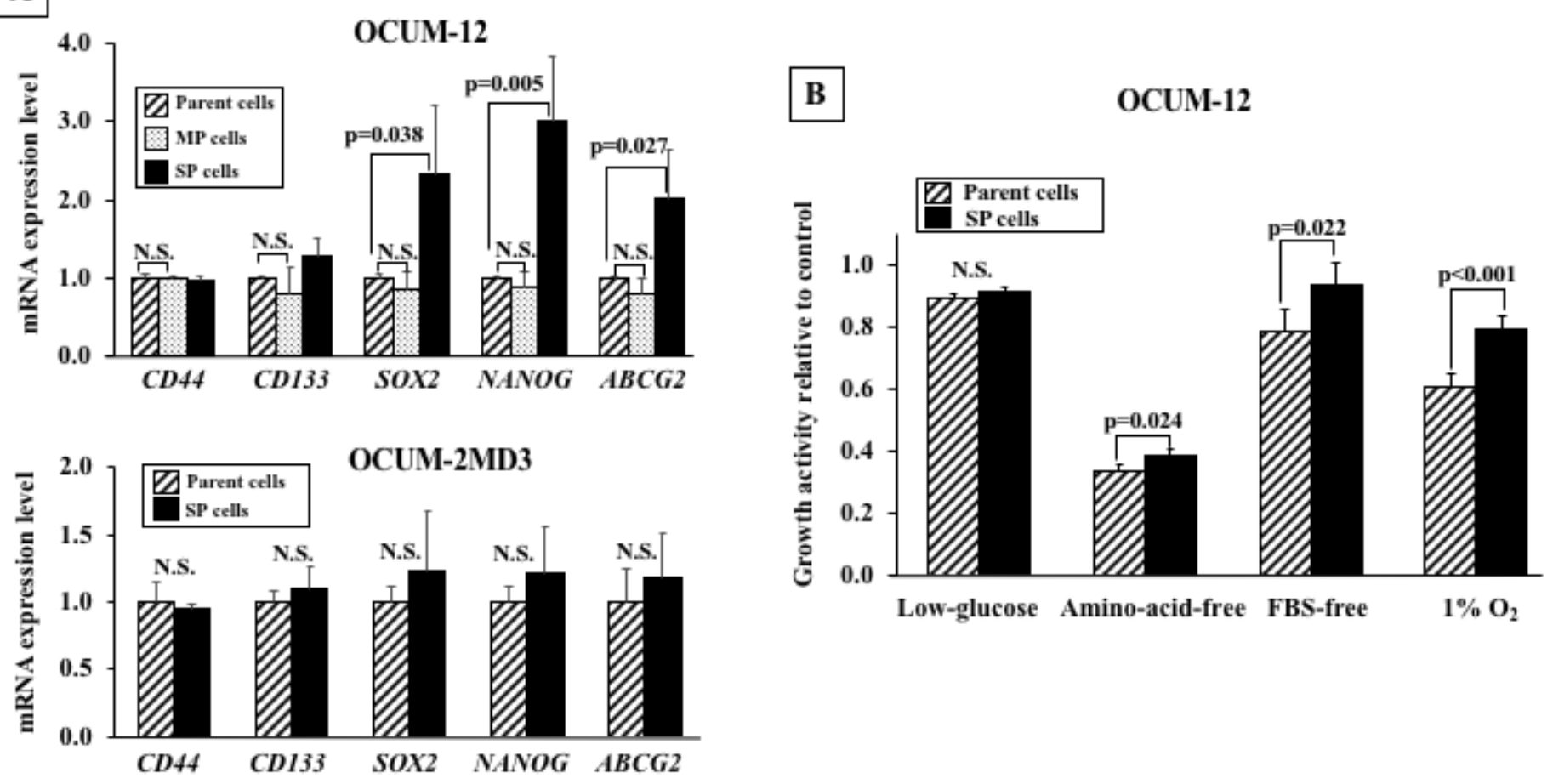

Figure 2

(A) Expression of stem cell markers. The mRNA expression levels of SOX2, NANOG, and ABCG2 were significantly higher in the OCUM-12/SP cells $(2.31-, 3.00$-, and 2.02- fold; $p=0.038,0.005$, and 0.027 , respectively) in comparison to the parent OCUM-12 cells. On the other hand, no significant difference of stem cell markers was found between the parent OCUM-2MD3 cells and the OCUM-2MD3/SP cells. (B) Proliferation activity of cancer cells under starvation and hypoxic stress. The viability of SP cells was significantly high under amino-acid-free, FBS-free, and $1 \% 02$ conditions $(0.38$ and $0.34 ; p=0.024,0.94$ and $0.79 ; p=0.022,0.80$ and $0.61 ; p<0.001$, relative to control; respectively), but was not significant under the low-glucose condition. 
Figure 3. Togano S. et al.

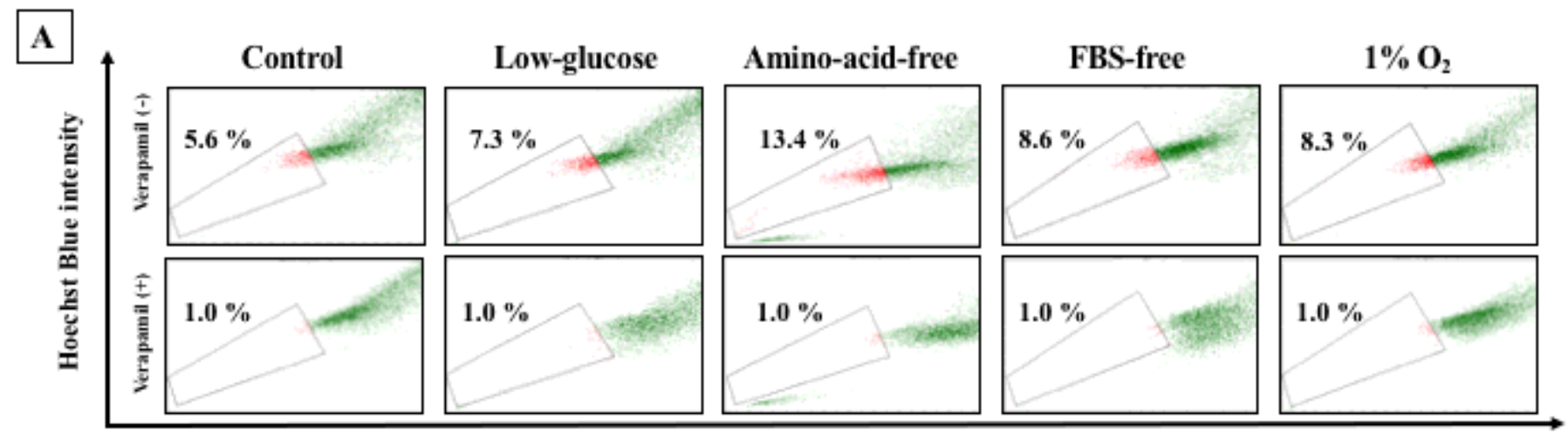

Hoechst Red intensity

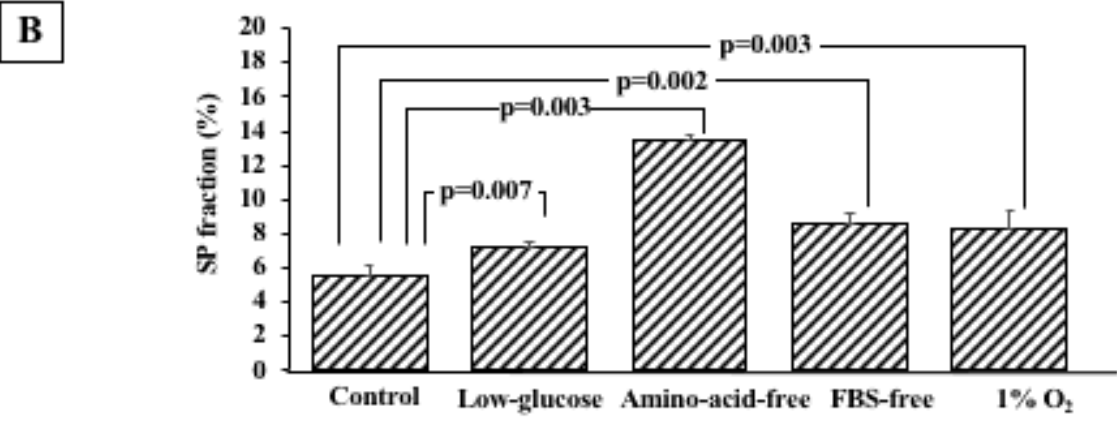

Figure 3

The SP fraction under starvation and hypoxic stress. (A) Representative picture of SP fraction under starvation and hypoxic stress. (B) The SP fraction was significantly high under starvation stress and hypoxic stress in comparison to the parent cells. The SP fractions under the low-glucose-medium, aminoacid-free medium, FBS-free medium, and $1 \% 02$ conditions were $7.3 \pm 0.2 \%(p=0.007), 13.2 \pm 0.4 \%$ $(p=0.003), 7.9 \pm 0.7 \%(p=0.002)$, and $7.7 \pm 1.0 \%(p=0.003)$ in comparison to the parent cells, respectively. 
Figure 4. Togano S. et al.

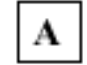

Low-glucose

Amino-acid-free

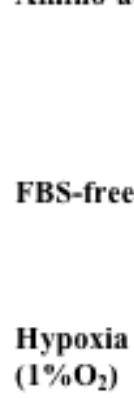

Control

\section{cells}

$\frac{\text { SP cells }}{\mathrm{CQ}(-) \quad \mathrm{CO}(+)}$

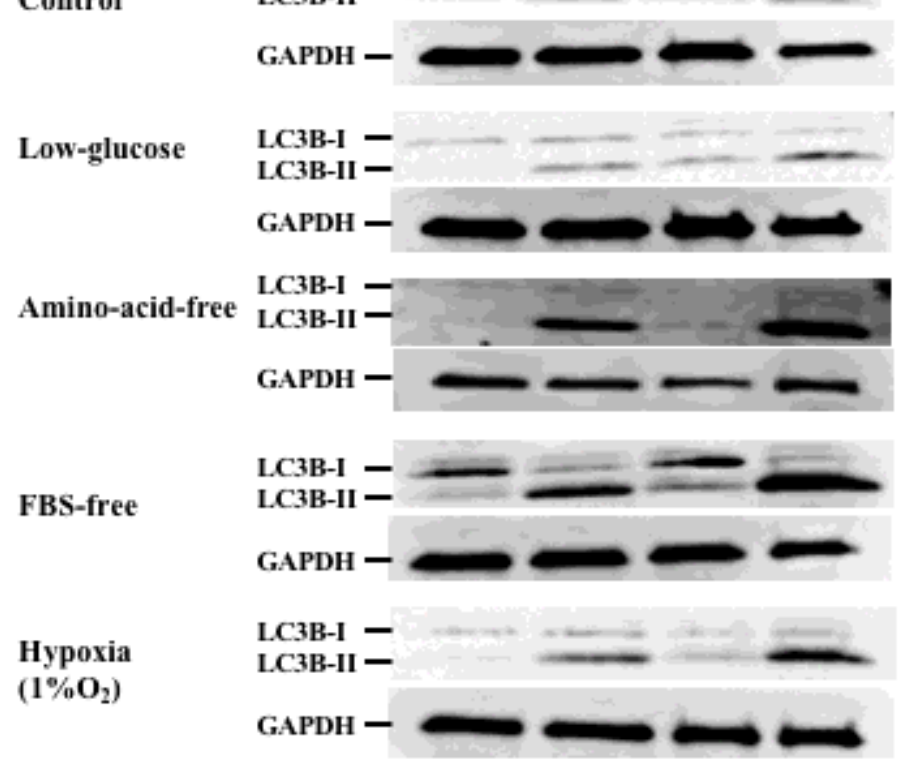

\section{B}

$\square$ Parent eells
Control

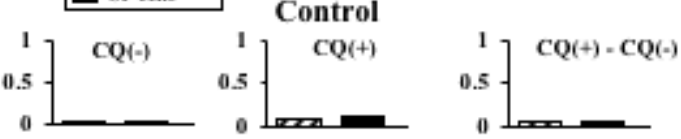

Low-glucose

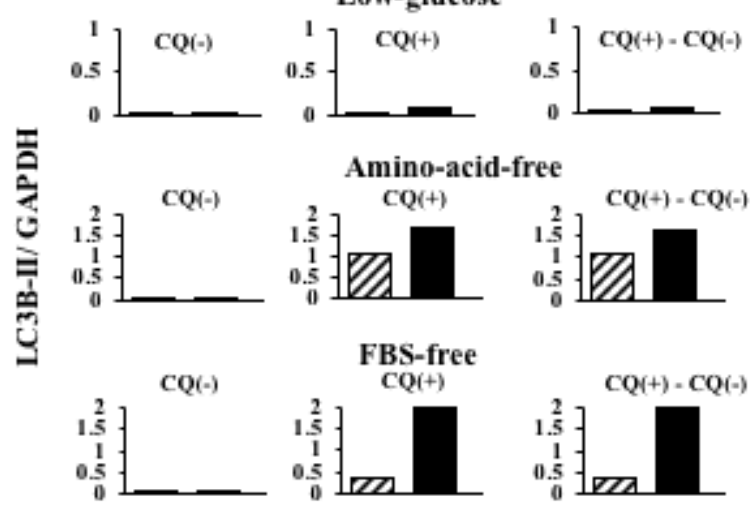

Hypoxia $\left(1 \% \mathrm{O}_{2}\right)$

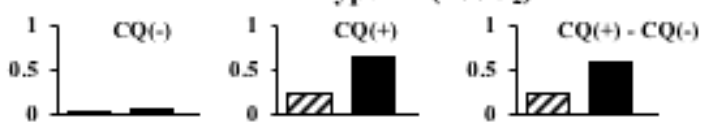

Figure 4

(A) Autophagy flux assay. (B) Autophagic flux was determined by subtracting the band intensity of the LC3-II western blot in the presence of CQ (CQ+) and the corresponding treatment in the absence of CQ (CQ-). The expression of LC3-II was higher in the OCUM-12/SP cells than in the parent OCUM-12 cells under amino-acid-free, FBS-free, and 1\%02 conditions (LC3/GAPDH ratio (CQ+) - LC3/GAPDH ratio (CQ-); 1.61 and $1.07,2.19$ and $0.35,0.58$ and 0.22 , respectively). The difference in LC3-II expression was greatest under the FBS-free medium. The LC3-II expressions under the control medium and low-glucose medium were slight $(0.04$ and $0.06,0.07$ and 0.02 , respectively). 
Figure 5. Togano S. et al.

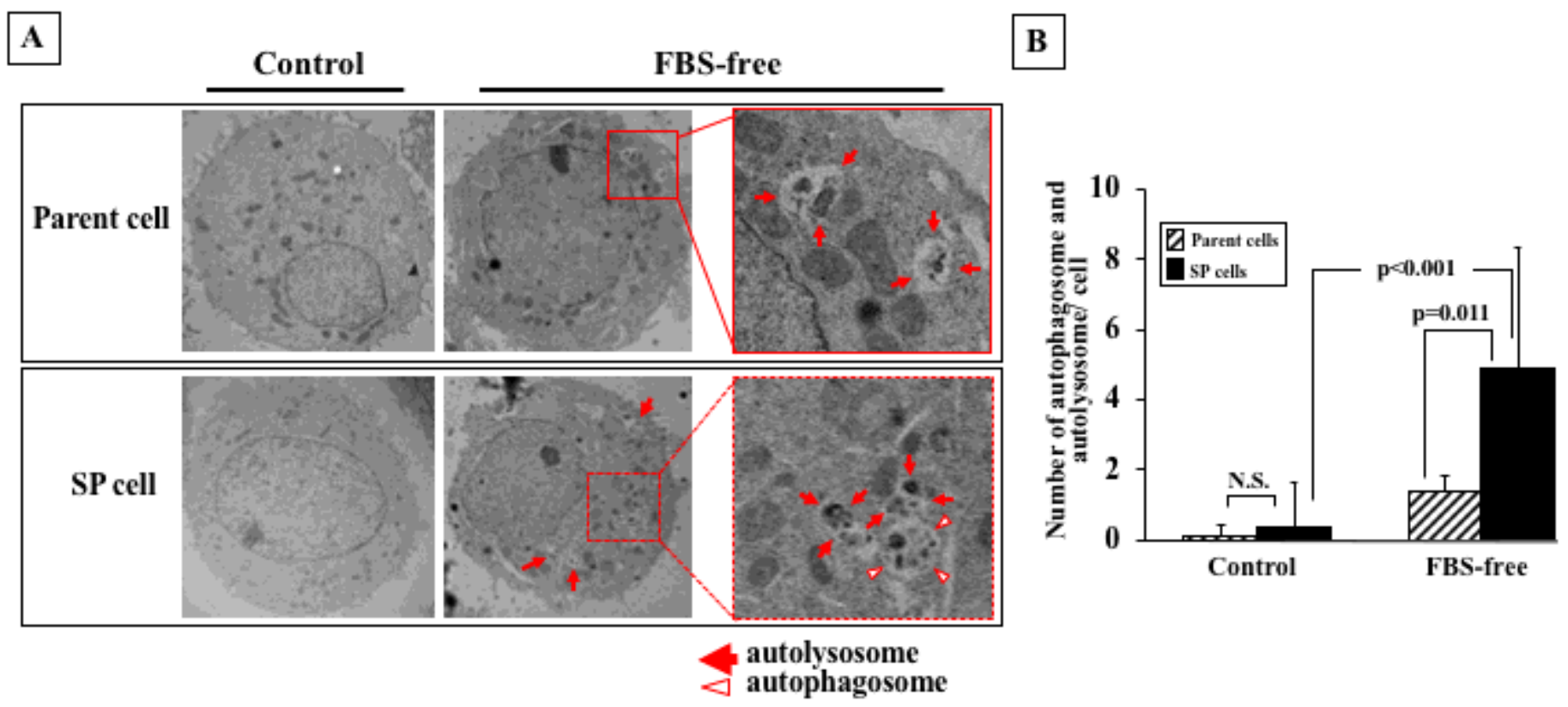

Figure 5

Autophagy under FBS starvation. (A) Electron microscopic pictures of autophagosomes and autolysosomes. (B) There was no significant difference between the OCUM-12/SP cells and the parent OCUM-12 cells in the control medium, but a significant $(p=0.011)$ increase in the number of autophagosomes and autolysosomes in the OCUM-12/ SP cells was observed under the FBS-free medium. 


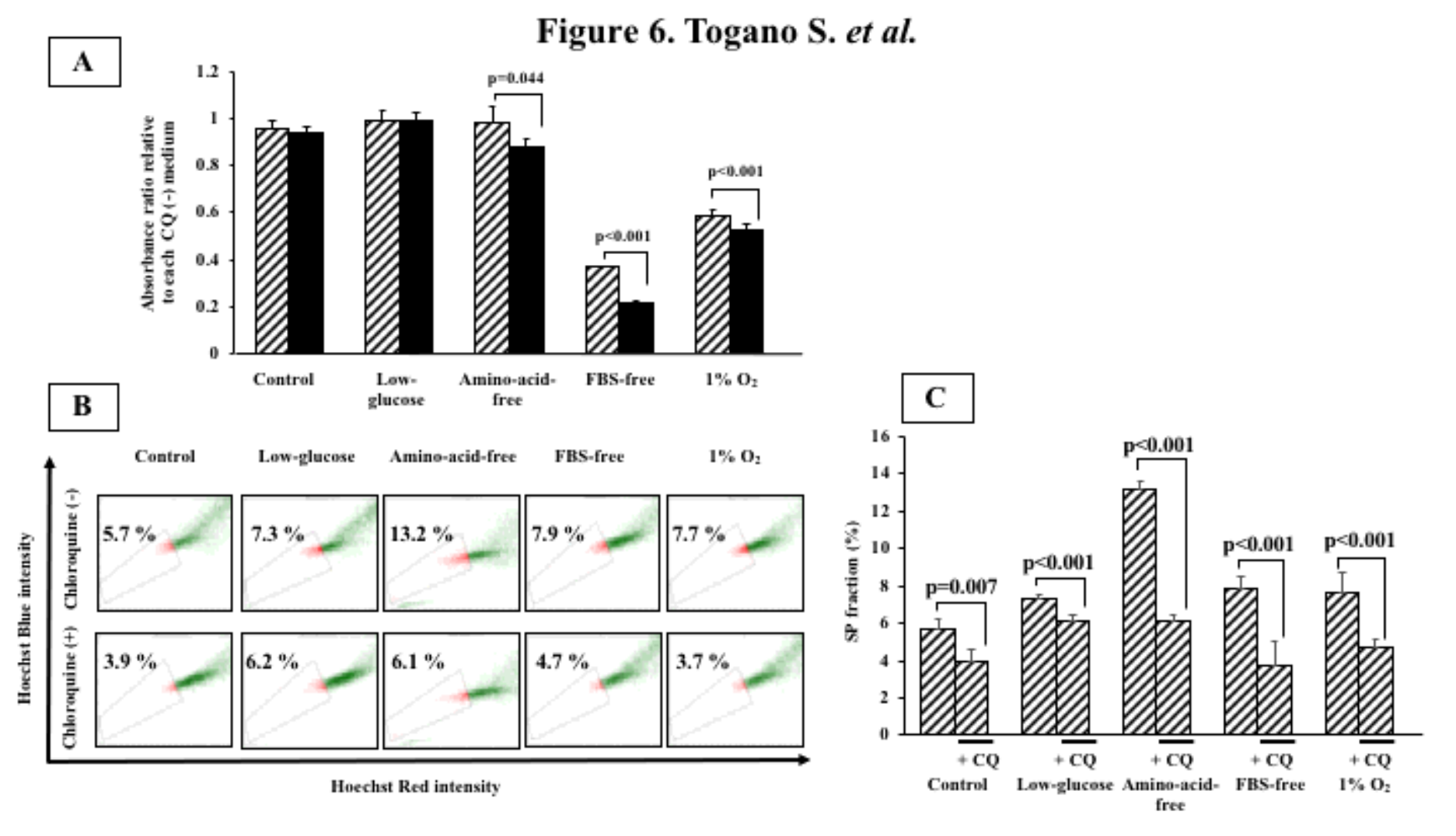

Figure 6

(A) The cytotoxicity of the autophagy inhibitor on the parent OCUM-12 cells and the OCUM-12/SP cells. CQ significantly decreased the viability of the OCUM-12/SP cells under amino-acid-free medium, FBS-free medium, and $1 \% 02$ conditions (absorbance ratio relative to each $\mathrm{CQ}(-)$ medium; 0.88 and $0.99 ; \mathrm{p}=0.044$, 0.21 and $0.37 ; p<0.001,0.53$ and $0.59 ; p<0.001$, respectively). (B) Effect of the autophagy inhibitor on the SP fraction of OCUM-12 under starvation and hypoxic stress. The SP fraction was decreased under all conditions including in the control medium following the addition of CQ. (C) The SP fraction in the OCUM12 cells was significantly reduced with CQ under amino-acid-free medium (13.2 to 6.1\%), FBS-free medium ( 7.9 to $3.7 \%$ ), and $1 \% 02$ conditions ( 7.7 to $4.7 \%$ ) compared to the control medium.

\section{Supplementary Files}

This is a list of supplementary files associated with this preprint. Click to download.

- SupplementaryMaterial.docx

- Figures1.tiff 